\title{
Pain-like behaviors and local mechanisms involved in the nociception experimentally induced by Latrodectus curacaviensis spider venom
}

\author{
Pedro Santana Sales Lauria ${ }^{a}$, Luciana Lyra Casais-e-Silva ${ }^{b}$, Renan Fernandes do Espírito-Santo ${ }^{c}$, \\ Claudio Maurício Vieira de Souza ${ }^{\mathrm{d}}$, Russolina Benedeta Zingali ${ }^{\mathrm{e}}$, Marjolly Brígido Caruso ${ }^{\mathrm{e}}$, \\ Milena Botelho Pereira Soares ${ }^{\mathrm{c}, \mathrm{f}}$, Cristiane Flora Villarreal ${ }^{\mathrm{a}, \mathrm{c}, *}$

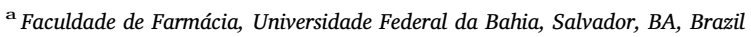 \\ ${ }^{\mathrm{b}}$ Instituto de Ciências da Saúde, Universidade Federal da Bahia, Salvador, BA, Brazil \\ c Instituto Gonçalo Moniz FIOCRUZ, Salvador, BA, Brazil \\ d Instituto Vital Brasil, Niterói, RJ, Brazil \\ e Instituto de Bioquímica Médica Leopoldo de Meis, Universidade Federal do Rio de Janeiro, Rio de Janeiro, RJ, Brazil \\ ${ }^{\mathrm{f}}$ Centro de Biotecnologia e Terapia Celular, Hospital São Rafael, Salvador, BA, Brazil
}

\section{A R T I C L E I N F O}

\section{Keywords:}

Widow spider

Pain

Nociception

TRPV1

Histamine

Inflammation

\begin{abstract}
A B S T R A C T
The present study was undertaken to characterize the behavioral manifestations of nociception and the local mechanisms involved with the nociceptive response elicited by Latrodectus curacaviensis venom (LCV) in mice. After the intraplantar LCV inoculation, spontaneous nociception, mechanical and thermal nociceptive thresholds, motor performance, edema and cytokine levels were evaluated using von Frey filaments, hot/cold plate, rota-rod, plethismometer and ELISA, respectively. Analysis of LCV was performed by SDS-PAGE and chromatography. Intraplantar injection of LCV (1-100 ng/paw) induced intense and heat-sensitive spontaneous nociception, mediated by serotonin and bradykinin receptors, TRPV1 channels, as well as by transient local inflammation. LCV (0.1-10 ng/paw) induced mechanical allodynia, which was reduced by the local pretreatment with H1 receptor or TRPV1 antagonists. Corroborating the TRPV1 involvement, in thermal nociception assays, LCV induced a similar response to that of capsaicin, a TRPV1 agonist, facilitating the response to noxious hot stimuli and inhibiting the response to cold noxious stimulation. LCV promoted mast cell degranulation, increased IL-1 $\beta$ paw levels, but did not produce a relevant edematogenic effect. Analysis of LCV components showed a predominance of high molecular weight proteins. This work provides the first mechanistic hypothesis to explain the local pain induced by LCV, the most frequent clinical symptom of human envenomation.
\end{abstract}

\section{Introduction}

Latrodectus (Araneae, Theridiidae) is a widespread genus of medically important spiders that causes thousands of venomous bites in humans around the world annually (Bücherl, 1972; Chippaux and Alagón, 2008). L. curacaviensis, one of the species found in Brazil (Levi, 1959), is the main responsible for human latrodectism in this country (Lucas, 2003; Souza, 2012). Latrodectism syndrome is characterized by neuromuscular manifestations, such as muscle cramps, involuntary contractions and hypertonicity, leading to rigidity of the abdomen and lower limbs. This syndrome is also associated with facies latrodectismica, characterized by the facial muscles twisted in a grimace, besides blepharitis, rhinitis, cheilitis and trismus of masseters (Araújo and Souza,
1988; Lira-da-Silva et al., 1995; Maretic, 1983).

The most frequent symptom of $L$. curacaviensis bite is intense burning local pain. Bitten patients also report generalized muscle pain, which intensifies over time, leading the victim to a state of physical and mental exhaustion (Araújo and Souza, 1988; Lira-da-Silva et al., 1995; Maretic, 1983).

In fact, widow spider bites are described as the most painful spider envenomation (Sylvie, 2015). Nevertheless, the mechanisms by which Latrodectus spp. venoms elicit pain are so far unknown. Reflecting this knowledge gap, the therapeutic approaches used in bitten patients aiming the pain control are often inadequate, considering that in most of them analgesia does not reach satisfactory levels (Antoniou et al., 2014; Offerman et al., 2011).

\footnotetext{
Abbreviations:LCV, Latrodectus curacaviensis venom

* Corresponding author at: Faculdade de Farmácia, Universidade Federal da Bahia, Rua Barão de Jeremoabo s/n, Ondina, Salvador, BA, CEP 40.170-115, Brazil. E-mail address: cfv@ufba.br (C.F. Villarreal).
} 
The understanding of the mechanisms of venom-induced pain may contribute to a better therapeutic approach for bitten patients, as well as for developing specific pharmacological tools to alleviate their suffering. Additionally, the characterization of the nociception induced by L. curacaviensis venom (LCV) represents an advance in the study of widow spiders' toxinology, which still is poorly understood (Yan and Wang, 2015). Therefore, the present study was undertaken to characterize the pain-like behaviors and the mechanisms and peripheral mediators involved in the LCV-induced nociception in mice.

\section{Material and methods}

\subsection{Animals}

Experiments were performed using male Swiss mice (25-30 g) from the Animal Facilities at the Institute Gonçalo Moniz (FIOCRUZ; Salvador, Brazil). Animals were housed in temperature-controlled rooms $\left(22 \pm 2{ }^{\circ} \mathrm{C}\right)$, under a 12:12 $\mathrm{h}$ light-dark cycle of artificial light, with access to food and water ad libitum. All behavioral tests were performed between 8:00 a.m. and 5:00 p.m. Animal care and handling procedures were in accordance with the recommendations established by IASP for the use of laboratory animals (Zimmermann, 1983) and complied with recommendations of the National Institutes of Health guide for the care and use of Laboratory animals (NIH, 8023). Experiments were approved by the Ethics Committee for Animal Experimentation of UFBA (CEUA-ICS; reference number 084/2015). Every effort was made to minimize the number of animals used and to avoid any discomfort.

\subsection{L. curacaviensis venom (LCV)}

LCV was obtained by the electrical stimulation of female $L$. curacaviensis spiders from Itaipuaçu (Maricá, RJ, Brazil), kindly provided by Vital Brazil Institute (Niterói, RJ, Brazil). The protocol was approved by the Ministério do Meio Ambiente, Instituto Chico Mendes de Conservação da Biodiversidade (ICMBio. Permit number: SISBIO $\mathrm{n}^{\circ}$ 55391-1). LCV was diluted in Milli-Q water and stored at $-80^{\circ} \mathrm{C}$ until use. The protein content in the venom was determined by the method of Bradford (1976) using SpectraMax 190 Absorbance Microplate Reader (Molecular Devices, CA, USA), and the tested doses were expressed as nanograms of total protein per paw.

\subsection{Drugs}

Capsazepine, capsaicin, compound 48/80 (C48/80), methysergide, HOE 140, indomethacin and dexamethasone were purchased from Sigma (St. Louis, MO, USA). Diazepam was obtained from Cristália (Itapira, SP, Brazil). Promethazine was obtained from Sanofi (São Paulo, SP, Brazil). C48/80, promethazine, methysergide, HOE 140 and dexamethasone were diluted in saline. Capsazepine was initially dissolved in DMSO and then diluted in saline, so that the final concentration of DMSO was $<1 \%$. Indomethacin was dissolved in Tris- $\mathrm{HCl}$ $0.1 \mathrm{M}, \mathrm{pH} 7.8$.

\subsection{Spontaneous nociceptive behavior}

Spontaneous nociceptive behavior was evaluated after intraplantar (i.pl.) injection of different doses of LCV (0.01-100 ng/paw). Saline (vehicle) and formalin (Synth, São Paulo, SP, Brazil) 2.5\% were used as negative and positive controls, respectively. Mice were placed individually in glass chambers for $15 \mathrm{~min}$ to acclimate before the experiment and then removed for i.pl. administration. Mice were gently restrained while $20 \mu \mathrm{L}$ of saline, formalin or LCV was administered subcutaneously to the plantar region of the right hind paw using a 30gauge needle. Following injection, mice were returned to the glass chambers for a 30-minute observation period. A mirror was placed behind the chamber to enable unhindered observation of the injected paw. The nociception score was determined by counting the time the animal spent licking, biting, shaking or protecting the inoculated paw during the observation time (Dubuisson and Dennis, 1977).

\subsection{Mechanical nociceptive threshold - von Frey test}

Mice were injected via i.pl. with different doses of LCV (0.01-10 ng/ paw) or saline (vehicle) and the threshold to mechanical stimuli was measured with von Frey filaments (Stoelting; Chicago, IL, USA). Mechanical nociceptive thresholds were evaluated daily 3 days before (baseline) the experimental day and at different time points after inoculation. In a quiet room, mice were placed in acrylic cages with wire grid floors $15 \mathrm{~min}$ before the test. A tilted mirror placed under the grid provided a clear view of the mice hind paws. The inoculated paw was touched with a series of filaments with logarithmically incremental stiffness (0.008-4g) until they were slightly bend. A positive response was characterized by the abrupt removal of the touched paw. The mechanical nociceptive threshold was calculated by the up-and-down method (Dixon, 1965). Values represent the filament weight (g) to which the animals respond in $50 \%$ of presentations.

\subsection{Thermal nociception to hot and cold stimuli}

Mice were injected via i.pl. with different doses of LCV (0.01-10 ng/ paw), saline (vehicle) or capsaicin $(1 \mu \mathrm{g} / \mathrm{paw})$ and the thermal nociception to hot or cold stimuli was measured in the hot plate or cold plate test, respectively. The responses were evaluated daily 3 days before (baseline) the experimental day and at different time points after inoculation. In the hot plate test, mice were placed on the plate (Teca; Chicago, IL, USA) at $55 \pm 0,1{ }^{\circ} \mathrm{C}$ and the latency until the paw withdrawal reflex was recorded. The thermal threshold for hot stimuli was represented as the latency time in seconds. In order to minimize the probability of skin damage, the cut-off time was $15 \mathrm{~s}$ and the time between two consecutive trials in the same animal was at least $30 \mathrm{~s}$ (Eddy and Leimbach, 1953). In the cold plate test, mice were placed on the plate (Teca) at $-2,5 \pm 0,1^{\circ} \mathrm{C}$ and observed for a 5 -minute observation period. The time in seconds during which mice were able to maintain the injected paw in contact with the cold surface was determined (Jasmin et al., 1998).

\subsection{Motor function assay - rota-rod test}

Considering the neurotoxic properties of LCV, the rota-rod test was performed to rule out possible interference in the motor function of treated mice. The rota-rod apparatus (Insight; Ribeirão Preto, SP, Brazil) consists of a bar that rotates at a constant speed of $8 \mathrm{rpm}$ and mice need to walk forwards in order to avoid falling from it. The animals were selected previously by eliminating those mice that did not remain on the bar for two consecutive periods of 120 s. Mice were injected via i.pl. with LCV (100 ng/paw) or saline, or via intraperitoneal (i.p.) with diazepam $(10 \mathrm{mg} / \mathrm{kg}$, reference drug). Thirty minutes later mice were challenged to remain on the rota-rod for three consecutive periods of $120 \mathrm{~s}$, and the results were expressed as the average time they resist in the bar without falling (Nascimento et al., 2016).

\subsection{Peripheral mechanisms of LCV-induced nociception}

In order to investigate possible mechanisms and peripheral mediators involved in LCV-induced nociception, classical pharmacological assays were performed with different antagonists / inhibitors. Mice were pretreated via i.pl. route with capsazepine (TRPV1 antagonist, $0.2 \mu \mathrm{g} / \mathrm{paw}$ ) (Srebro et al., 2016), promethazine $\left(\mathrm{H}_{1}\right.$ histamine receptor antagonist, $100 \mu \mathrm{g} / \mathrm{paw}$ ) (Oliveira et al., 2011), methysergide (non-selective 5-HT receptor antagonist, $500 \mathrm{ng} / \mathrm{paw}$ ) (Gewehr et al., 2013), HOE $140\left(\mathrm{~B}_{2}\right.$ bradykinin receptor antagonist, $5 \mu \mathrm{g} / \mathrm{paw}$ ) (Chacur et al., 
2002) or indomethacin (non-selective COX inhibitor, $100 \mu \mathrm{g} / \mathrm{paw}$ ) (Ferreira et al., 1978) and $30 \mathrm{~min}$ later received i.pl. injection of LCV at $10 \mathrm{ng} /$ paw. Dexamethasone (corticosteroid anti-inflammatory drug, $50 \mu \mathrm{g} /$ paw) (Ferreira et al., 1997) was administered $60 \mathrm{~min}$ before the LCV injection. The effects of these pretreatments on LCV-induced nociception were evaluated in both spontaneous nociception and mechanical nociceptive threshold.

\subsection{Mesenteric mast cell degranulation assay}

Mice were intraperitoneally treated with LCV $(66 \mu \mathrm{g} / \mathrm{kg}), \mathrm{C} 48 / 80$ $(0.6 \mathrm{mg} / \mathrm{kg}$, mast cell degranulation inducing agent) or saline $(500 \mu \mathrm{L}$, vehicle). Thirty minutes or $6 \mathrm{~h}$ later, mice were terminally anesthetized with halothane. The mice mesentery was carefully removed and mounted on a glass slide. The material was fixed in $4 \%$ formaldehyde for $2 \mathrm{~h}$ at $4{ }^{\circ} \mathrm{C}$ and then stained with Giemsa stain for $15 \mathrm{~min}$. Mast cell degranulation was determined by counting 100 cells, using a manual cell counter, and determining the percentage of cells with granules outside the cytoplasmic membrane limits (Galvão-Nascimento et al., 2010; Kwasniewski et al., 1998).

\subsection{Edematogenic activity}

The edematogenic activity of LCV was evaluated after i.pl. injection of different doses of the venom (0.01-100 ng/paw). Saline and formalin (5\%) were used as negative and positive controls, respectively. The induction of local edema was evidenced by the measurement of the paw volume using a plethysmometer apparatus (Ugo Basile; Comerio, Italy), immediately before (baseline) and at different time points after LCV (Lima et al., 2013). The magnitude of paw edema was calculated as the percentage of the paw volume increase relative to the baseline.

\subsection{Cytokines measurement by ELISA}

The skin paw levels of cytokines were determined as previously described (Lima et al., 2018). Mice were inoculated by i.pl. route with LCV (10 ng/paw) or saline (vehicle), while the naive group represented mice not experimentally manipulated. Skin tissues were removed from the paws 0.5 or $3 \mathrm{~h}$ after inoculation, in mice terminally anesthetized with halothane from each experimental group. Tissue proteins were extracted from $100 \mathrm{mg}$ tissue/mL phosphate buffered saline (PBS) to which $0.4 \mathrm{M} \mathrm{NaCl}, 0.05 \%$ Tween 20 and protease inhibitors $(0.1 \mathrm{mM}$ PMSF, $0.1 \mathrm{mM}$ benzethonium chloride, $10 \mathrm{mM}$ EDTA, and $20 \mathrm{KI}$ aprotinin $\mathrm{A} / 100 \mathrm{ml}$ ) were added. The samples were centrifuged for $10 \mathrm{~min}$ at $3000 \mathrm{~g}$ and the supernatant was frozen at $-80^{\circ} \mathrm{C}$ for later quantification. Interleukin-1 $\beta$ (IL-1 $\beta$ ) and tumor necrosis factor- $\alpha$ (TNF- $\alpha$ ) levels were estimated using commercially available immunoassay ELISA kits for mice (R\&D System; Minneapolis, MN, USA), according to the manufacturer's instructions. The results were expressed as picograms of cytokine per milligram of protein.

\subsection{SDS-PAGE analysis}

LCV was extracted using a glass capillary after electrical stimulation of ten female spiders, diluted in milli-Q water and frozen in liquid nitrogen. The protein content of this pool was measured by Pierce ${ }^{\mathrm{TM}} \mathrm{BCA}$ Protein Assay Kit (Thermo Fisher Scientific; Waltham, MA, USA) and $20 \mu \mathrm{g}$ of this material was denatured and reduced in SDS loading buffer for $5 \mathrm{~min}$, for further analysis by 1D polyacrylamide gel (SDS-PAGE $12 \%$ ) in the BioRad system under the conditions: $120 \mathrm{v}, 30 \mathrm{~mA}, 1: 30 \mathrm{~h}$ (Laemmli, 1970). PeppermintStick ${ }^{\mathrm{TM}}$ Phosphoprotein Molecular Weight (Thermo Fisher Scientific) was used as standard proteins in order to evaluate the distribution of molecules present in the venom. The gel was stained with $0.1 \%$ of Coomassie brilliant blue G (CBB-G-250).

\subsection{Separation of LCV proteins by chromatography}

A $500 \mu \mathrm{g}$ LCV sample diluted in milli-Q water was centrifuged at $10.000 \mathrm{rpm}$ for $5 \mathrm{~min}$ at room temperature and the supernatant was collected. A solution of $0.1 \%$ trifluoroacetic acid (TFA) was added to the supernatant until the final volume of $2 \mathrm{~mL}$. This mixture was applied to a $2 \mathrm{~mL}$ loop, and separated by high-performance liquid chromatography (HPLC) using a reverse-phase (RP) column Teknokroma Europa protein $\mathrm{C} 18(25 \mathrm{~cm} \times 0.4 \mathrm{~cm}, 5 \mathrm{~mm}$ particle size, $300 \AA$ pore size) in a Shimadzu 10AVP system. The column was equilibrated for 20 min with solvent A $(0.1 \%$ TFA), previous to the injection of the sample. The elution of the proteins was performed by a gradient of solvent B $(0.1 \%$ TFA in $100 \%$ of acetonitrile) at a flow rate of $1 \mathrm{~mL} /$ min. Initially the elution was performed at isocratic gradient at $5 \%$ of $B$ for $10 \mathrm{~min}$, followed by a gradient of $5-80 \%$ of B for $70 \mathrm{~min}$, an isocratic gradient at $80 \%$ of B for $5 \mathrm{~min}$, a decrease in the gradient of 85$5 \%$ for $1 \mathrm{~min}$ and a new isocratic gradient at $5 \%$ for $10 \mathrm{~min}$ (Castro et al., 1998). The elution was monitored at $214 \mathrm{~nm}$, and the experiments were made in duplicates.

\subsection{Venom heating}

In order to obtain information on the thermolability of the nociceptive constituents of LCV, the effect of heating the venom on its nociceptive properties was evaluated. The venom was heated at $90{ }^{\circ} \mathrm{C}$ for $10 \mathrm{~min}$ (Gewehr et al., 2013), and then injected by i.pl. route (10 ng/ paw) in mice. The spontaneous nociceptive behavior was quantified as described above.

\subsection{Statistical analysis}

Data are presented as means \pm standard error of the means (SEM) of measurements made on 6 mice per group. Comparisons between three or more treatments were made using one-way ANOVA with Tukey's post-hoc test, or for repeated measures, two-way ANOVA with Bonferroni's post-hoc test. Data were analyzed using GraphPad Prism 6 computer software (GraphPad, San Diego, CA, USA). Statistical differences were considered to be significant at $\mathrm{p}<0.05$.

\section{Results}

\subsection{LCV induces intense and dose-dependent spontaneous nociception}

Spontaneous nociception was the initial parameter used to characterize the pronociceptive properties of LCV by quantifying pain-like behaviors. As shown in Fig. 1A, i.pl. injection of LCV at 1 ( $\mathrm{p} \leq 0.01$ ), 10 and $100 \mathrm{ng} / \mathrm{paw}(\mathrm{p} \leq 0.001)$ caused an intense and dose-dependent spontaneous nociceptive response in mice. The representation of nociceptive behavior over time (Fig. 1B) shows that the pain-like behaviors started quickly after venom inoculation and exhibited a continuous pattern over the observation period, unlike the biphasic response pattern induced by formalin.

\section{2. $L C V$ reduces the mechanical nociceptive threshold}

LCV i.pl. injection at $0.1,1$, or $10 \mathrm{ng}$ /paw evoked marked and dosedependent reduction of the mechanical nociceptive threshold ( $\mathrm{p} \leq 0.001$ ) relative to saline-treated mice. This pronociceptive state, named mechanical allodynia, persisted for up to $24 \mathrm{~h}$ after injection (Fig. 2).

\subsection{LCV alters thermal nociceptive thresholds in a capsaicin-like fashion}

Fig. 3 shows the effects of LCV local injection on nociceptive thresholds for hot (panel A) or cold (panel B) thermal stimulation in mice. LCV-inoculated mice exhibited reduced paw withdrawal latency 

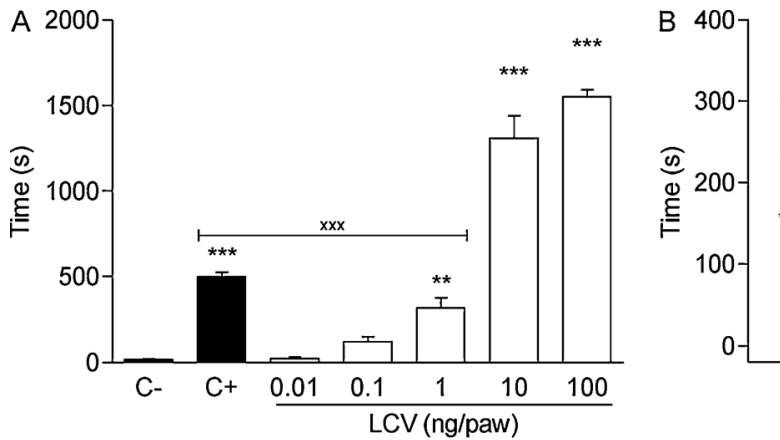

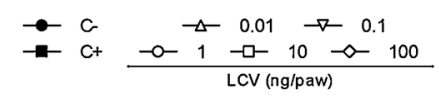

*

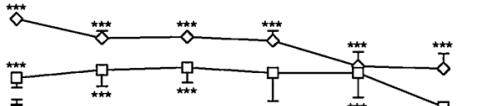
范 atial times that mice spent exhibiting painlike behaviors over a 30-minute observation period. Data are expressed as means \pm SEM $(\mathrm{n}=6) . * \mathrm{p} \leq 0.05, * * \mathrm{p} \leq 0.01, * * * \mathrm{p} \leq 0.001$ compared with C- group. ${ }^{\mathrm{xxx}} \mathrm{p} \leq 0.001$ compared with LCV 10 and $100 \mathrm{ng} /$ paw groups. (A) One-way ANOVA followed by Tukey's test. (B) Two-way ANOVA followed by Bonferroni's test.

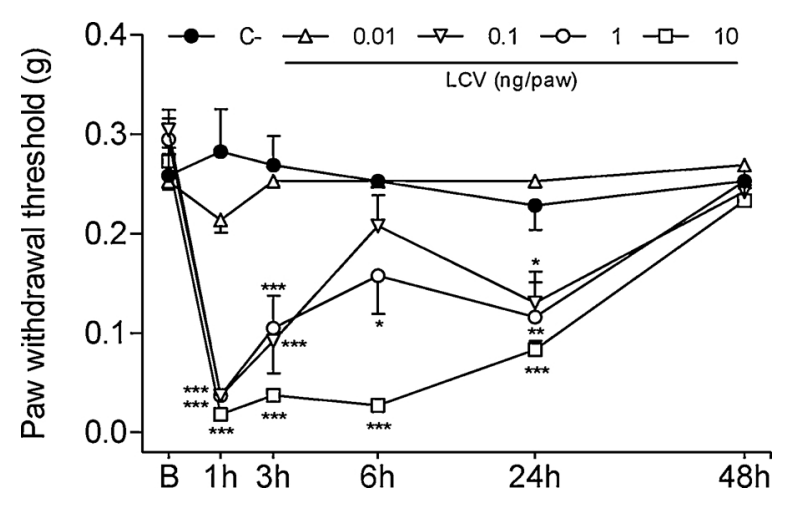

Fig. 2. LCV reduces the mechanical nociceptive threshold in mice. Mice were inoculated via i.pl. with LCV (0.01-10 ng/paw) or saline (C-). The mechanical nociceptive threshold (axis of ordinates) was measured at different times following the inoculation (axis of abscissas) and was represented as the filament weight $(\mathrm{g})$ in which the animal responds in $50 \%$ of the presentations. The baseline (B) represents the mean threshold before the day of the experiment. Data are expressed as means $\pm \operatorname{SEM}(n=6) .{ }^{*} \mathrm{p} \leq 0.05,{ }^{* *} \mathrm{p} \leq 0.01$, $* * * \mathrm{p} \leq 0.001$ compared with C- group. Two-way ANOVA followed by Bonferroni's test.

in the hot plate test (Fig. 3A). This pronociceptive effect was statistically significant at all tested doses (0.01-10 ng/paw; $\mathrm{p} \leq 0.05)$, with no dose-dependence, and persisted for up to $24 \mathrm{~h}$ after the intraplantar administration. Capsaicin $(1 \mu \mathrm{g} / \mathrm{paw})$ also reduced the nociceptive threshold to hot thermal stimuli ( $\mathrm{p} \leq 0.05$ ).

On the other hand, i.pl. injection of LCV reduced the nociceptive response in the cold plate test. LCV-treated mice ( 1 or $10 \mathrm{ng} / \mathrm{paw}$ ) were able to keep the inoculated paw in contact with the cold surface for a longer time compared to the control group ( $\mathrm{p} \leq 0.05$; Fig. $3 \mathrm{~B}$ ), exhibiting reduced nociceptive behavior for up to $6 \mathrm{~h}$ after administration. The intraplantar injection of capsaicin $(1 \mu \mathrm{g} / \mathrm{paw})$ reduced nociceptive behavior at 3 and $6 \mathrm{~h}$ post-injection. Importantly, capsaicin and LCV induced similar patterns of modulation on the nociceptive thermal response in both tests.

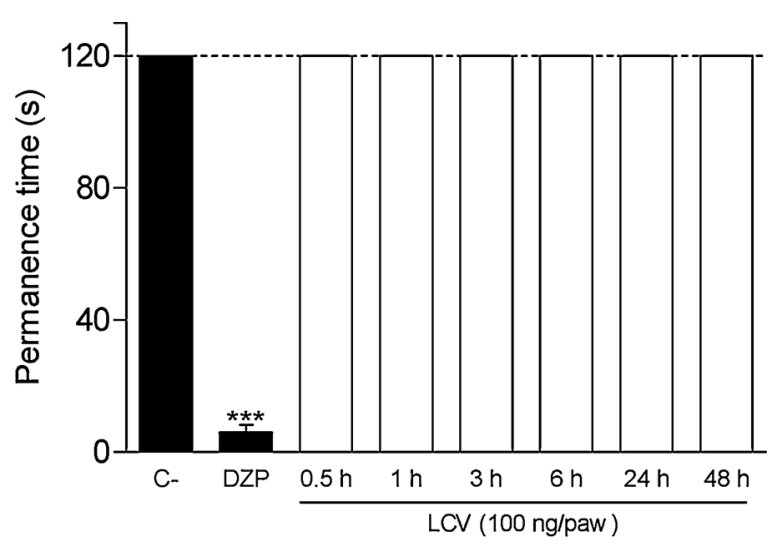

Fig. 4. Effect of LCV on motor function of mice. Mice received an i.pl. injection of LCV (100 ng/paw) or saline (C-). Diazepam (DZP; $10 \mathrm{mg} / \mathrm{kg}$, i.p.) was the reference drug. The permanence time of mice on the rotating bar (axis of ordinates) was measured at different times following the injection (axis of abscissas). The dotted line indicates the cut-off time of $120 \mathrm{~s}$. Data are expressed as means \pm SEM $(n=6) .{ }^{* * *} \mathrm{p} \leq 0.001$ compared with C- group. Two-way ANOVA followed by Bonferroni's test.

\subsection{LCV inoculation does not induce motor function impairment}

Since Latrodectus spp. venoms are known to induce neurotoxicity, the motor function of LCV-treated mice was evaluated using the rotarod test (Fig. 4). This test was performed with LCV at $100 \mathrm{ng} / \mathrm{paw}$, the highest dose tested in nociception assays. The permanence time of mice on the rota-rod was not influenced by i.pl. injection of LCV (100 ng/ paw), indicating that this venom did not induce detectable motor impairment.

\subsection{Local mediators involved with LCV-induced spontaneous nociception}

After establishing the behavioral profile of LCV-induced nociception, the mechanisms by which this venom exerts pronociceptive activity were investigated in classical pharmacological assays with
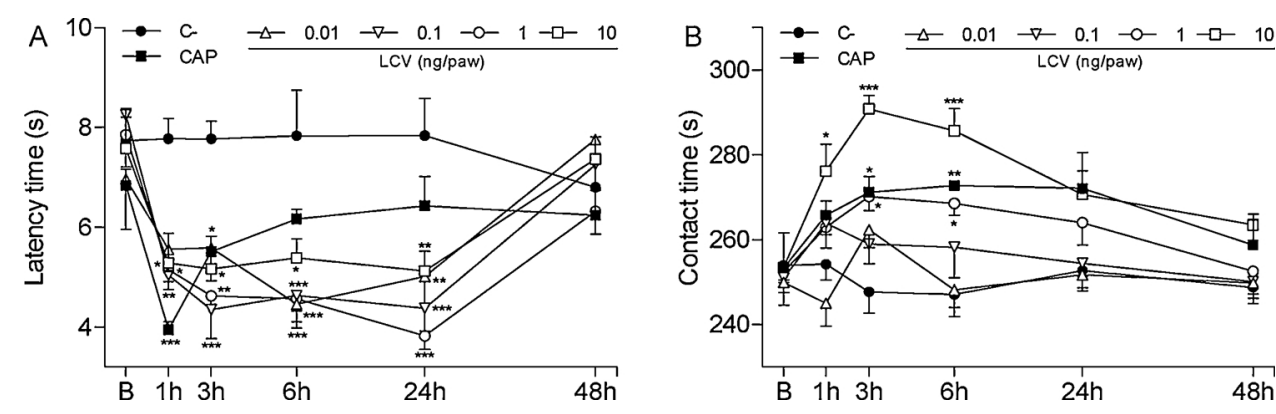

Fig. 3. Influence of LCV on nociceptive responses to hot or cold thermal stimuli. Mice were inoculated via i.pl. with LCV (0.01-10 ng/paw), capsaicin (CAP, $1 \mu \mathrm{g} / \mathrm{paw}$ ) or saline (C-). In the hot plat test (Panel A), paw withdrawal latency (ordinates axis) was measured at different times following the inoculation (abscissas axis). In the cold plate test (Panel B), the contact time of the mice paw with the cold surface (ordinates axis) was counted at different time points following the inoculation (abscissas axis). The baseline (B) represents the mean latency or contact time

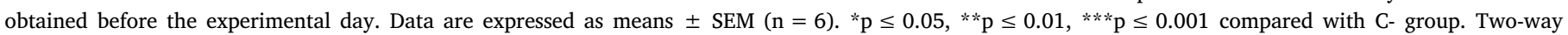
ANOVA followed by Bonferroni's test. 


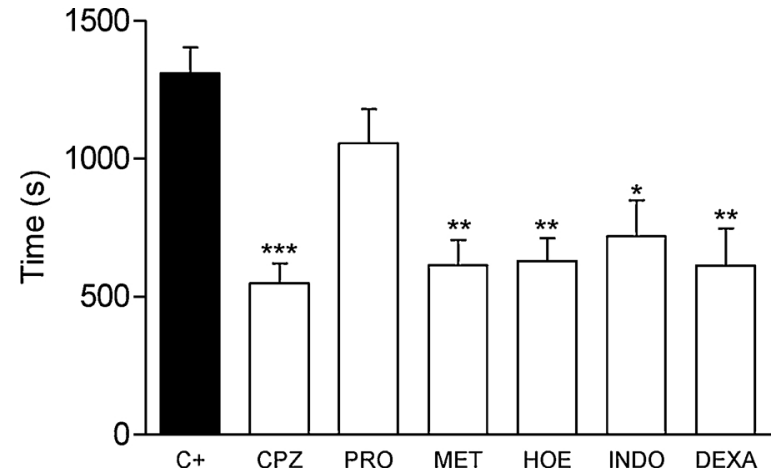

Fig. 5. Effects of pharmacological inhibition of different nociceptive systems on LCV-induced spontaneous nociception. Mice were pretreated by i.pl. route with capsazepine (CPZ; $0.2 \mu \mathrm{g} / \mathrm{paw}, 30 \mathrm{~min}$ before), promethazine (PRO; $100 \mu \mathrm{g}$ / paw, $30 \mathrm{~min}$ before), methysergide (MET; $500 \mathrm{ng} / \mathrm{paw}, 30 \mathrm{~min}$ before), HOE 140 (HOE; $5 \mu \mathrm{g} / \mathrm{paw}, 30 \mathrm{~min}$ before), indomethacin (INDO; $100 \mu \mathrm{g} / \mathrm{paw}$, $30 \mathrm{~min}$ before) or dexamethasone (DEXA; $50 \mu \mathrm{g} / \mathrm{paw}, 60 \mathrm{~min}$ before) and then received i.pl. injection of LCV (10 ng/paw). Group $\mathrm{C}+$ represents mice that received LCV (10 ng/paw) after saline pretreatment. Bars show the total time in seconds that mice spent exhibiting pain-like behaviors over a 30-minute observation period. Data are expressed as means \pm SEM $(n=6)$. *p $\leq 0.05$, $* * \mathrm{p} \leq 0.01, * * * \mathrm{p} \leq 0.001$ compared with $\mathrm{C}+$ group. One-way ANOVA followed by Tukey's test.

inhibitors and antagonists. The impacts of pharmacological inhibition of different systems related with pain on LCV-induced spontaneous nociceptive behavior were evaluated. In this series of studies, the maximum nociceptive dose of LCV (10 ng / paw) was used. Intraplantar pretreatment with capsazepin $(0.2 \mu \mathrm{g} / \mathrm{paw}$; TRPV1 antagonist), methysergide ( $500 \mathrm{ng} / \mathrm{paw}$; non-selective 5 -HT receptor antagonist) or HOE $140\left(5 \mu \mathrm{g} / \mathrm{paw}\right.$; $\mathrm{B}_{2}$ bradykinin receptor antagonist), partially prevented the spontaneous nociceptive behavior induced by LCV (Fig. 5; $\mathrm{p} \leq 0.01)$. The anti-inflammatory drugs indomethacin $(100 \mu \mathrm{g} /$ paw; non-selective COX inhibitor) and dexamethasone $(50 \mu \mathrm{g} / \mathrm{paw}$; corticosteroid drug) also reduced the LCV-induced spontaneous nociception ( $\mathrm{p} \leq 0.05$ and $\mathrm{p} \leq 0.01$, respectively), whereas promethazine $\left(100 \mu \mathrm{g} / \mathrm{paw} ; \mathrm{H}_{1}\right.$ histamine receptor antagonist) induced no statistically significant effect. None of these antagonists altered per se the nociceptive threshold and the motor function of mice (data not shown).

\subsection{Activation of $H 1$ histamine receptors and TRPV1 channels contributes to LCV-induced allodynia}

The mechanisms and mediators involved with the LCV-induced mechanical allodynia were also investigated. As shown in Fig. 6, the pretreatment with capsazepine $(0.2 \mu \mathrm{g} / \mathrm{paw})$ markedly reduced the mechanical allodynia 3, 6 and $24 \mathrm{~h}(\mathrm{p} \leq 0.001)$ after LCV injection. Promethazine pretreatment $(100 \mu \mathrm{g} / \mathrm{paw})$ induced a delayed reduction of LCV-induced allodynia, being statistically significant at 6 and $24 \mathrm{~h}$ after treatment $(\mathrm{p} \leq 0.001)$. Local pretreatment with methysergide

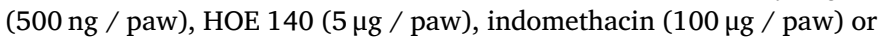
dexamethasone $(50 \mu \mathrm{g} / \mathrm{paw})$ did not affect mechanical allodynia induced by LCV.

\subsection{LCV induces marked mast cells degranulation}

As mast cells are relevant sources of histamine, and the $\mathrm{H}_{1}$ receptor antagonist, promethazine, reduced LCV-induced allodynia, the effect of LCV on mast cells degranulation was assessed. Considering the delayed pattern of promethazine effects on LCV-induced nociception, its possible action on mast cells was evaluated $6 \mathrm{~h}$ post-administration. As shown in Fig. 7, intraperitoneal administration of LCV $(66 \mu \mathrm{g} / \mathrm{kg})$ caused marked degranulation of mast cells $6 \mathrm{~h}$ post-injection, as compared to the saline-treated group (Fig. 7D; $\mathrm{p} \leq 0.001$ ). Mast cells from

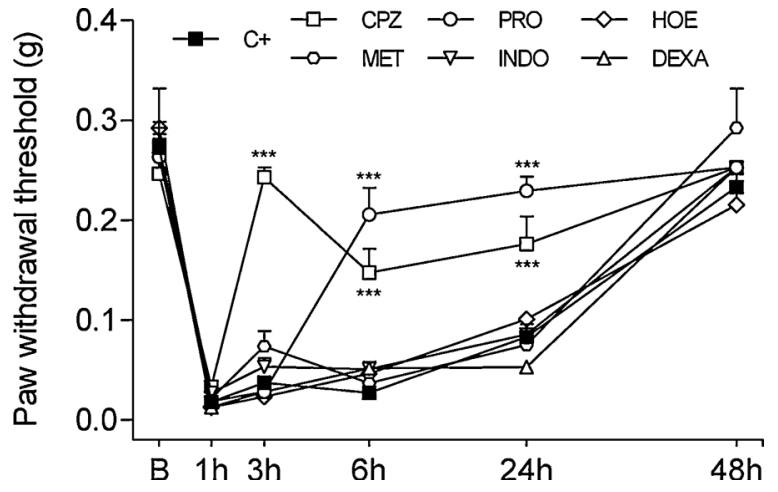

Fig. 6. Effects of pharmacological inhibition of different nociceptive systems on the mechanical allodynia elicited by LCV. Mice were pretreated by i.pl. route with capsazepine (CPZ; $0.2 \mu \mathrm{g} / \mathrm{paw}, 30 \mathrm{~min}$ before), promethazine (PRO; $100 \mu \mathrm{g} /$ paw, $30 \mathrm{~min}$ before), methysergide (MET; $500 \mathrm{ng} / \mathrm{paw}, 30 \mathrm{~min}$ before), HOE 140 (HOE; $5 \mu \mathrm{g}$ /paw, $30 \mathrm{~min}$ before), indomethacin (INDO; $100 \mu \mathrm{g} / \mathrm{paw}$, $30 \mathrm{~min}$ before) or dexamethasone (DEXA; $50 \mu \mathrm{g} / \mathrm{paw}, 60 \mathrm{~min}$ before) and then received i.pl. injection of $\mathrm{LCV}(10 \mathrm{ng} / \mathrm{paw})$. Group $\mathrm{C}+$ represents mice that received LCV (10 ng/paw) after saline pretreatment. The mechanical nociceptive threshold (axis of ordinates) was measured at different times following the venom injection (axis of abscissas) and was represented as the filament weight (g) in which the animal responds in $50 \%$ of the presentations. The baseline (B) represents the mean threshold before the day of the experiment. Data are expressed as means \pm SEM $(n=6)$. ${ }^{* * *} \mathrm{p} \leq 0.001$ compared with $\mathrm{C}+$ group. Two-way ANOVA followed by Bonferroni's test.

saline-treated mice (Fig. 7A) presented a regular shape with no extravasated granules, while mice treated with C $48 / 80(0.6 \mathrm{mg} / \mathrm{kg}$; Fig. $7 \mathrm{~B}$, $\mathrm{p} \leq 0.001$ ) or LCV (Fig. 7C, $\mathrm{p} \leq 0.001$ ) showed a higher amount of cells with morphological alterations and extracellular granules, indicating its activation.

\subsection{LCV induces discrete and short-lasting local edema}

Considering that anti-inflammatory drugs reduced LCV-induced spontaneous nociception, a possible proinflammatory action of LCV was also investigated. LCV induced a slight and quickly reverted paw edema when injected locally at 10 or $100 \mathrm{ng} /$ paw (Fig. 8; p $\leq 0.05$ ). The edematogenic effect of LCV was lower and short-lasting when compared to formalin-induced paw edema.

\section{9. $L C V$ promotes increase in local levels of $I L-1 \beta$}

Aiming to investigate the local mediators involved in the pronociceptive effects of LCV, the paw levels of the proinflammatory cytokines TNF- $\alpha$ and IL-1 $\beta$ were measured after the i.pl. injection of LCV in mice. The paw levels of TNF- $\alpha$ were not different in LCV-treated (10 ng/paw) mice relative to naïve or saline-treated mice (Fig. 9A). On the other hand, the local levels of IL- $1 \beta$ were increased $3 \mathrm{~h}$ after LCV inoculation when compared with naïve or saline-treated mice (Fig. 9B; $\mathrm{p} \leq 0.001$ ). Furthermore, local pretreatment with dexamethasone $(50 \mu \mathrm{g} / \mathrm{paw})$ completely prevented the increase of IL- $1 \beta$ levels induced by LCV (Fig. 9B; $\mathrm{p} \leq 0.001$ ).

\subsection{LCV contains predominantly high molecular weight proteins}

Aiming to evaluate the protein distribution of LCV and its complexity, two different techniques were performed and the results are summarized in Fig. 10. SDS-PAGE analysis revealed a pattern of proteins from the LCV sample comprising molecules with a broad range of masses, most of which were observed from 116.25 to $23.6 \mathrm{kDa}$, whereas only a few molecules between 23.6 and $14.4 \mathrm{kDa}$ were detected. In addition, there were differences in expression levels between proteins, with higher abundance of high molecular weight molecules (116.25 to 

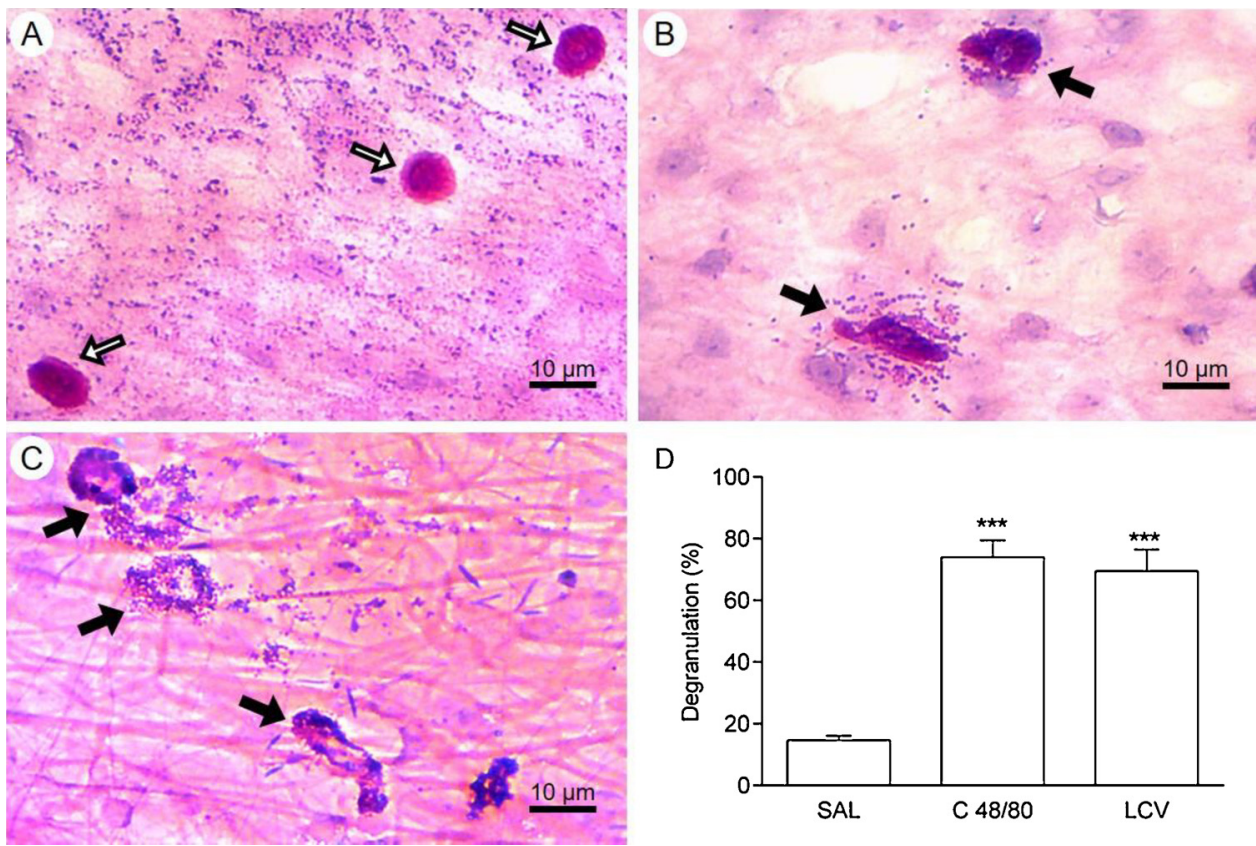

Fig. 7. LCV-induced mesenteric mast cell degranulation. Mice were injected by intraperitoneal route with (A) saline $(500 \mu \mathrm{L}$, SAL), (B) $\mathrm{C} 48 / 80(0.6 \mathrm{mg} / \mathrm{kg})$ or (C) LCV $(66 \mu \mathrm{g} / \mathrm{kg})$. The mesentery was removed 30 min (A and $\mathrm{B}$ ) or $6 \mathrm{~h}(\mathrm{C})$ after treatments, fixed and stained with Giemsa. Panel D shows the quantification of mast cell degranulation, represented by the percentage of cells with granules outside the cytoplasmic membrane limits. White arrows point to non-activated mast cells. Black arrows point to activated mast cells with extravasated granules. Data are expressed as means \pm SEM $(\mathrm{n}=5)$. $* * * \mathrm{p} \leq 0.001$ compared with saline-treated group. One-way ANOVA followed by Tukey's test.

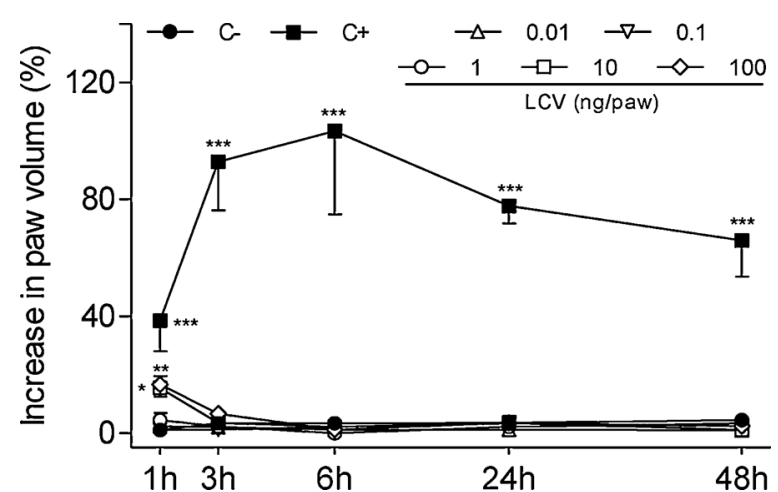

Fig. 8. Edematogenic effect of LCV. Mice were injected via i.pl. with LCV (0.01-100 ng/paw), saline (C-) or 5\% formalin (C+). Paw edema, measured at $1,3,6,24$ and $48 \mathrm{~h}$ after intraplantar injection, was represented as the percentage increase in paw volume (axis of ordinates). Data are expressed as means $\pm \operatorname{SEM}(\mathrm{n}=6) .{ }^{*} \mathrm{p} \leq 0.05,{ }^{* *} \mathrm{p} \leq 0.01$, ***p $\leq 0.001$ compared with $\mathrm{C}$ group. Two-way ANOVA followed by Bonferroni's test.

$45 \mathrm{kDa})$.

The reverse-phase (C-18) chromatography analysis revealed that the venom proteins were eluted with solvent B $(0.1 \%$ TFA in $100 \%$ of acetonitrile) along the gradient of $5-65 \%$ (retention time of 10-70 min). The major components of the venom were observed between $15-60 \%$ of the gradient (retention time of $20-65 \mathrm{~min}$ ), with a population of peaks with the highest abundance around $42-50 \%$ (retention time of $47-55 \mathrm{~min})$. It is most likely that these peaks are equivalent to the most abundant proteins observed in the electrophoresis gel, although further analysis are needed in order to identify these molecules.

\subsection{Heating LCV abolishes its pronociceptive properties}

In order to obtain information on the thermolability of the nociceptive components of LCV, a venom sample was subjected to a heating protocol prior to the in vivo test. As shown in Figs. 1 and 11, the i.pl. injection of LCV (10 ng/paw) induced a robust spontaneous nociceptive behavior ( $p \leq 0.001$ ). However, the heated LCV completely lost its nociceptive properties ( $\mathrm{p} \leq 0.001$ ), indicating the thermolabile nature of the nociceptive toxins present in the venom.

Mice were injected via i.pl. with LCV (10 ng/paw; C +), saline (C-) or heated LCV (10 ng/paw). Bars show the total time in seconds that mice spent exhibiting pain-like behaviors over a 30-minute observation period. Data are expressed as means \pm SEM $(n=6)$. ***p $\leq 0.001$ compared with $\mathrm{C}+$ group. One-way ANOVA followed by Tukey's test.

\section{Discussion}

The present study characterized, for the first time, the pronociceptive properties of the venom of a Latrodectus spider in mice. Behavioral, pharmacological and immune assays showed that LCV induces an

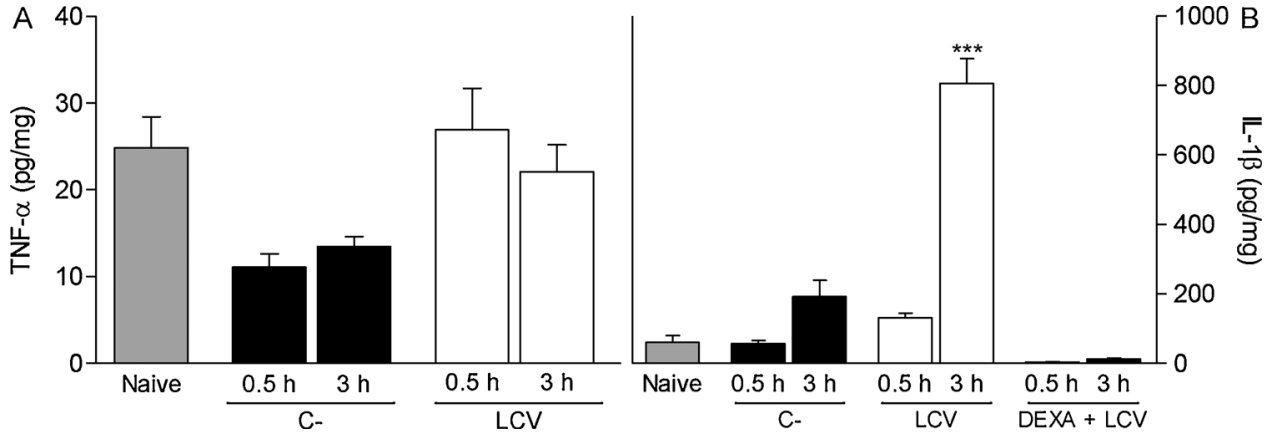

$* * * \mathrm{p} \leq 0.001$ compared to the remaining groups. One-way ANOVA followed by Tukey's test.
Fig. 9. Effect of LCV on the local levels of proinflammatory cytokines. Mice were injected with LCV (10 ng/paw) or saline (C-) by i.pl. route. Alternatively, mice were pretreated with dexamethasone $(50 \mu \mathrm{g} / \mathrm{paw})$ by i.pl. route and $60 \mathrm{~min}$ later received an i.pl. injection of LCV (10 ng/paw) (DEXA + LCV). Skin tissues samples were collected 0.5 or $3 \mathrm{~h}$ after treatments for (A) TNF- $\alpha$ and (B) IL-1 $\beta$ determination by ELISA. Naive group consists of mice that did not receive any experimental manipulation. The results are represented as picograms of cytokine per milligram of protein. Data are expressed as means \pm SEM $(n=5)$. 


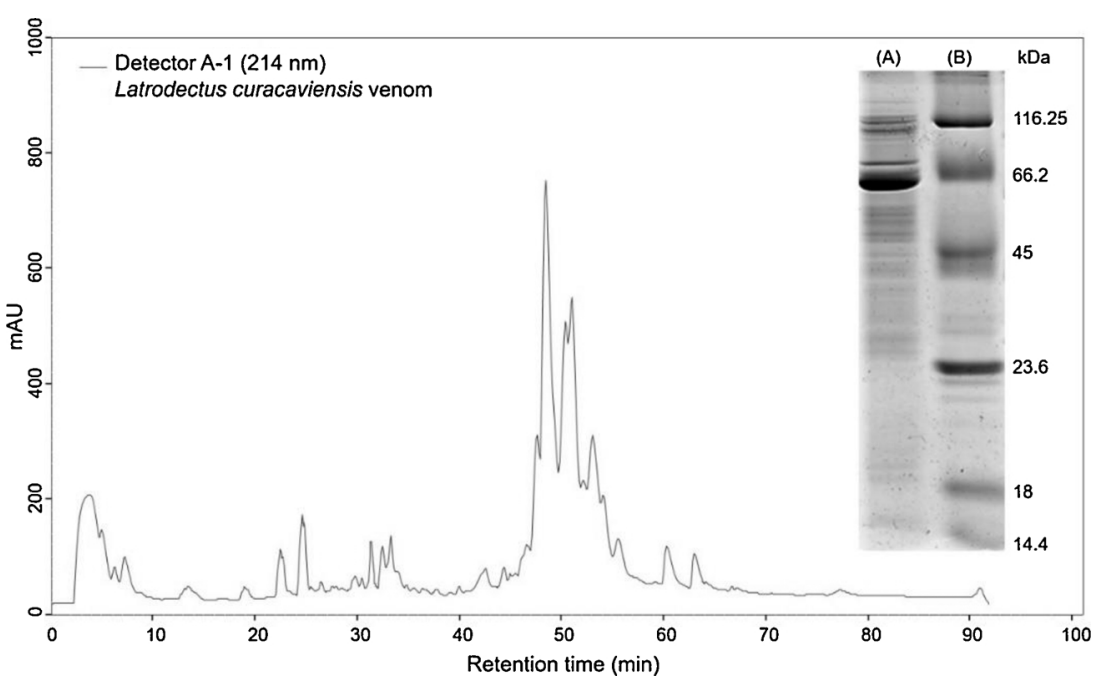

Fig. 10. SDS-PAGE and reverse-phase chromatography analysis of LCV. The panel on the right shows the SDS-PAGE (12\%) analysis of LCV. (A) Distribution of the proteins present in the LCV sample. (B) PeppermintStick ${ }^{\mathrm{TM}}$ Phosphoprotein Molecular Weight used as standard proteins. The chromatogram shows the protein profile of LCV after separation in RPcolumn Teknokroma Europa protein C18 $(25 \mathrm{~cm} \times 0.4 \mathrm{~cm}$, $5 \mathrm{~mm}$ particle size, $300 \AA$ pore size) in a Shimadzu 10AVP system. The elution of the proteins was performed by a gradient of solvent B $(0.1 \%$ TFA in $100 \%$ of acetonitrile) at a flow rate of $1 \mathrm{~mL} / \mathrm{min}$ and monitored at $214 \mathrm{~nm}$.

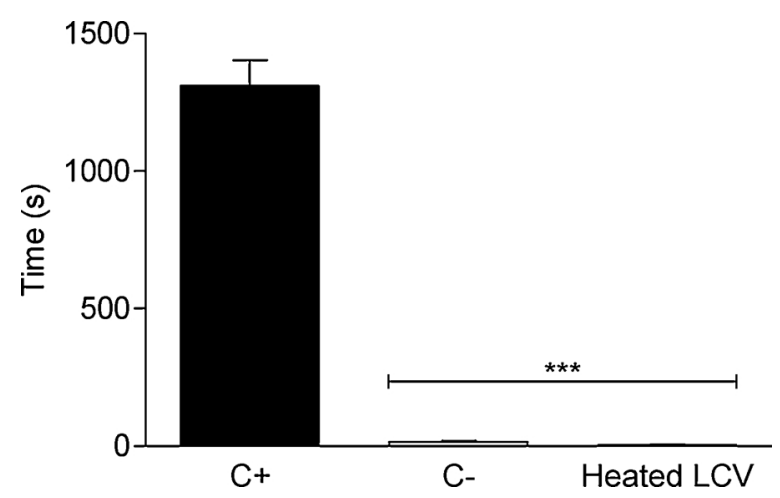

Fig. 11. Effect of previous heating on the pronociceptive activity of LCV.

intense pronociceptive state mediated by different systems. While initial spontaneous nociception was mediated by TRPV1 channels, activation of serotoninergic and bradykinin receptors and an inflammatory component, the development of nociceptive sensitization, characterized by mechanical allodynia, was mediated by TRPV1 channels and histamine system.

The spontaneous nociceptive behavior of LCV-inoculated mice started quickly, a few seconds after the i.pl. injection, remaining consistently intense through the 30-minute observation period. In addition, LCV-injected mice developed a nociceptive sensitization state, which started $1 \mathrm{~h}$ and persisted for up to $24 \mathrm{~h}$ after administration. This pronociceptive state was characterized by mechanical allodynia, indicated by the reduction of the paw withdrawal threshold. These results are in agreement with the available clinical data of the accidents caused by $L$. curacaviensis in Brazil (Araújo and Souza, 1988; Lira-da-Silva et al., 1995), which describe intense local pain as the major symptom. Local painful manifestations of latrodectism may vary according to the etiologic agent. Whereas $L$. hasselti bites are immediately painful (Vetter and Isbister, 2008), L. tredecimguttatus bites are usually unnoticed, until local pain starts after several minutes (Pommier et al., 2005), suggesting the diversity of the nociceptive mechanisms of these venoms. In the present study, LCV inoculation in mice induced both immediate and long-lasting pronociceptive effects, possibly reflecting multiple mechanisms of action.

In fact, pharmacological assays demonstrated that different nociceptive systems contribute to spontaneous nociception and nociceptive sensitization induced by LCV. The LCV-induced spontaneous nociception was partially prevented by capsazepin, methysergide, HOE 140 and anti-inflammatory drugs, suggesting that TRPV1 channels, serotoninergic and bradykinin receptors and inflammatory mediators are involved in this response. Serotonin is a monoamine often found in the composition of spider venoms (Welsh and Batty, 1963), and constitutes an important mediator in the pain induced by Phoneutria nigriventer venom (Gewehr et al., 2013). The fact that serotonin has previously been identified as a component of venom of a Latrodectus spider, $L$. tredecimguttatus (Pansa et al., 1972), reinforces the hypothesis that this monoamine contributes to the nociception induced by LCV. Serotonin works peripherally as a inflammatory mediator, and its action may be either by direct activation of C fiber (Dray, 1995; Sommer, 2004) or by the induction of peripheral sensitization, which facilitates the effect of other pain mediators, such as bradykinin (Abbott et al., 1996; Dray, 1995; Sommer, 2004).

Bradykinin has long been thought to be a physiologic mediator of pain. Bradykinin $B_{2}$ receptors are constitutively expressed in nociceptive primary afferent fibers (Dray, 1995) and their activation has been knowingly involved with acute nociception, but not with sustained inflammatory pain nor persistent hyperalgesic states (Boyce et al., 1996; Dray, 1995; Perkins et al., 1993). Corroborating this idea, the present data showed that B2 receptor antagonism by HOE 140 reduced spontaneous nociception but not persistent nociceptive sensitization induced by LCV.

Both bradykinin and serotonin are pain mediators produced by tissues in response to tissue damage and inflammation. In the present study, bradykinin and serotonin receptor antagonists or anti-inflammatory drugs reduced by the same magnitude the LCV-induced spontaneous nociception. Therefore, a possible proinflammatory action of the venom was next investigated. The present data showed that LCV induces a slight and brief local inflammatory response. The local edema induced by intraplantar injection of LCV was rapidly reversed, suggesting the establishment of a local inflammatory process that is readily resolved. Consistent with this result, the anti-inflammatory drugs indomethacin or dexamethasone reduced early spontaneous nociception induced by LCV, but did not modify the venom-induced persistent allodynia.

Considering the important roles of IL-1 $\beta$ and TNF- $\alpha$ in inflammatory pain, a possible effect of LCV on the production/release of these proinflammatory cytokines was also investigated. LCV induced a local increase in IL- $1 \beta$ levels, but not TNF- $\alpha, 3 \mathrm{~h}$ after injection. Even though IL-1 $\beta$ may induce nociception and hyperalgesia (Ferreira et al., 1988), it does not seem to play a relevant role in LCV-induced nociception, because pretreatment with dexamethasone prevented the local increase of this cytokine, but not the establishment of mechanical allodynia.

Unlike the role of inflammation, TRPV1 channels appear to be essencial for the pronociceptive effects induced by LCV. Blockade of TRPV1 channels was the only pharmacological approach capable of preventing both early spontaneous nociception and persistent allodynia 
induced by LCV. TRPV1 is a nonselective cation channel activated by acid, highly expressed in sensory neurons, involved with physiological pain perception and different pronociceptive states (Jardín et al., 2017). The contribution of TRPV1 to the painful sensations triggered by different animal venoms is already well-established (Min et al., 2013), and the involvement of these channels with the biological effects of venoms and toxins of spiders has recently been proposed (Bohlen et al., 2010; Costa et al., 2000; Gewehr et al., 2013; Kitaguchi et al., 2005; Siemens et al., 2006; Zanchet and Cury, 2003). The results found in the present work are similar to those described for the Phoneutria nigriventer venom, which induces, under experimental conditions, spontaneous nociception and hyperalgesia through TRPV1 activation (Gewehr et al., 2013; Zanchet and Cury, 2003). The present data from thermal nociceptive tests corroborate the role of TRPV1 in the nociception induced by LCV, as proposed by the pharmacological studies. LCV induced a modulation pattern of thermal nociception similar to that induced by capsaicin, a known TRPV1 agonist (Caterina et al., 1997). LCV, like capsaicin, increased the mice response to hot thermal stimuli, while reduced the nociceptive response to cold stimuli. Capsaicin acts on thermosensitive neurons, as a TRPV1 agonist, enhancing the activity of hot-sensitive fibers and decreasing the activity of cold-sensitive fibers (Bölcskei et al., 2010; Hori et al., 1988; Tanimoto-Mori et al., 2008). Considering that LCV triggered effects consistent with the pattern of a TRPV1 agonist, the thermal nociception tests corroborate the pharmacological data suggesting the activity of LCV on TRPV1 channels.

Besides TRPV1, activation of histaminergic receptors also contributed to LCV-induced mechanical allodynia. Although histamine is present in different spider venoms (Boevé et al., 1995; Gewehr et al., 2013; Moore et al., 2009; Rash et al., 1998, 2000), in the pharmacological assay performed here, the histaminergic antagonist induced a delayed effect, suggesting that LCV is not the primary source of histamine. Instead, LCV may activate endogenous mechanisms of histamine release. Aiming to investigate this hypothesis, the ability of LCV to induce mast cells degranulation was evaluated, since these cells are the main endogenous sources of histamine (Graham et al., 1955). When injected systemically at a sub-lethal dose, LCV caused a marked degranulation of peritoneal mast cells, indicating that this cell type may be the endogenous source of histamine that contributes to the LCVinduced persistent allodynia. In fact, different animal venoms have been shown to promote their effects via mast cell activation (Casais-eSilva et al., 2016; Liu et al., 2007; Rattmann et al., 2008; Távora et al., 2016).

TRPV1 channels and H1 histaminergic receptors are co-expressed in some primary afferent fibers (Nicolson et al., 2002). Crosstalk between the signaling pathways of TRPV1 and H1 receptors has been described. Activation of $\mathrm{H} 1$ receptors deflagrates signaling pathways that culminate in the TRPV1 activation and sensitization, a phenomenon that has been considered important in the development of different pain conditions (Gao et al., 2016; Kajihara et al., 2010; Wouters et al., 2016). Considering that both TRPV1 channels and $\mathrm{H} 1$ receptors were involved in LCV-induced persistent allodynia, it is possible that the above described mechanisms contribute to the pronociceptive effects of LCV. However, further investigations are required to establish the intracellular pathways leading to the pronociceptive state induced by LCV.

Latrodectus venoms are complex mixtures of different toxic components with several biological roles, such as immobilization, killing and digestion of prey (Ushkaryov et al., 2004). The toxinology of black widow spiders is even more intricate because their toxins are not restricted to venom glands, but are also present in eggs, juvenile bodies and some body parts of adult spiders (Yan and Wang, 2015). The major toxic component for mammals that has been described in the $\mathbf{L a}$ trodectus venom is $\alpha$-Latrotoxin, a $131 \mathrm{kDa}$ protein (Frontali et al., 1976; Grasso, 1976; Ushkaryov et al., 2004). However, the role of other toxins from Latrodectus venom in human poisoning can be predicted, since the action of $\alpha$-Latrotoxin alone does not explain all clinical symptoms.

An initial characterization of LCV components was conducted here by SDS-PAGE and reverse-phase chromatography analysis, revealing that this venom contains a variety of proteins. LCV proteins have mainly high molecular weights and are more abundant in the range of $116.25-45 \mathrm{kDa}$. A previous study using a similar methodology identified 122 different proteins in L. tredecimguttatus venom, which are also predominantly high molecular weight compounds (Duan et al., 2008). Interestingly, proteins representing major components of LCV have a molecular weight below that of $\alpha$-Latrotoxin. When LCV was submitted to a heating protocol, its pronociceptive activity was completely abolished. This result indicates that the nociceptive toxins are thermolabile and, therefore, most likely are high molecular weight compounds, which has been demonstrated to be abundant in LCV composition. On the other hand, the role of small thermolabile peptides cannot be discarded, and further studies are needed in order to identify the LCV constituents responsible for the complex pronociceptive properties of this venom characterized here.

\section{Conclusion}

To the best of our knowledge, this is the first experimental demonstration of the nociceptive properties of a Latrodectus venom. Inoculation of LCV caused an intense spontaneous nociceptive behavior, persistent allodynia and nociceptive thermal threshold changes. The pronociceptive state induced by LCV involved different mechanisms, among which TRPV1 channels and histaminergic pathways are probably the most relevant. This work contributes to a better understanding of latrodectic syndrome and may be a useful starting point for establishing an improved pharmacological approach of bitten patients.

\section{Conflict of interest}

The authors declare that there are no conflicts of interest. The founding sponsors had no role in the design of the study; in the collection, analyses, or interpretation of data; in the writing of the manuscript, and in the decision to publish the results.

\section{Funding}

This work was supported by the Fundação de Amparo à Pesquisa do Estado da Bahia [grant number 11582/2015].

\section{Transparency document}

The Transparency document associated with this article can be found in the online version.

\section{References}

Abbott, F.V., et al., 1996. Activation of 5-HT2A receptors potentiates pain produced by inflammatory mediators. Neuropharmacology 35 (1), 99-110 1996.

Antoniou, G.N., et al., 2014. Latrodectus envenomation in Greece. Perm. J. 18 (4) 155-158.

Araújo, C.L., Souza, I.M., 1988. Estudo clínico e comparativo do latrodectismo na Bahia Revista da Sociedade Brasileira de Toxicologia 1, 53-55.

Boevé, J.L., et al., 1995. Quantity and quality of venom released by a spider (Cupiennius salei, Ctenidae). Toxicon 33 (10), 1347-1357.

Bohlen, C.J., et al., 2010. A bivalent tarantula toxin activates the capsaicin receptor, TRPV1, by targeting the outer pore domain. Cell 141 (5), 834-845.

Bölcskei, K., et al., 2010. Antinociceptive desensitizing actions of TRPV1 receptor agonists capsaicin, resiniferatoxin and $\mathrm{N}$-oleoyldopamine as measured by determination of the noxious heat and cold thresholds in the rat. Eur. J. Pain 14, 480-486.

Boyce, S., et al., 1996. Nociception and inflammatory hyperalgesia in $\mathrm{B}_{2}$ bradykinin receptor knockout mice. Immunopharmacology 33 (1), 333-335.

Bradford, M.M., 1976. A rapid and sensitive method for the quantitation of microgram quantities of protein utilizing the principle of protein-dye binding. Anal. Biochem. 72 (1-2), 248-254.

Bücherl, W., 1972. Invertebrados: As Aranhas, first ed. Edart, São Paulo.

Casais-e-Silva, L.L., et al., 2016. Lemnitoxin, the major component of Micrurus lemniscatus 
coral snake venom, is a myotoxic and pro-inflammatory phospholipase A2. Toxicol. Lett. 22 (1), 60-71.

Castro, H.C., et al., 1998. Bothroalternin, a thrombin inhibitor from the venom of Bothrops alternatus. Toxicon 36 (12), 1903-1912.

Caterina, M.J., et al., 1997. The capsaicin receptor: a heat-activated ion channel in the pain pathway. Nature 389 (6653), 816-824.

Chacur, M., et al., 2002. Bradykinin is involved in hyperalgesia induced by Bothrops jararaca venom. Toxicon 40 (1), 1047-1051.

Chippaux, J.P., Alagón, A., 2008. Envenimations et empoisonnements par les animaux venimeux ou vénéneux. VII: l'arachnidisme du Nouveau Monde. Médecine Tropicale 68 (3), 215-221.

Costa, S.K.P., et al., 2000. Involvement of vanilloid receptors and purinoceptors in the Phoneutria nigriventer spider venom-induced plasma extravasation in rat skin. Eur. J. Pharmacol. 391 (1), 305-315.

Dixon, W.J., 1965. The up-and-down method for small samples. J. Am. Stat. Assoc. 60 (312), 967-978.

Dray, A., 1995. Inflammatory mediators of pain. Br. J. Anaesth. 75, 125-131.

Duan, Z., et al., 2008. Proteomic analysis of Latrodectus tredecimguttatus venom for uncovering potential latrodectism-related proteins. J. Biochem. Mol. Toxicol. 22, 328-336.

Dubuisson, D., Dennis, S.G., 1977. The formalin test: a quantitative study of the analgesic effects of morphine, meperidine, and brain stem stimulation in rats and cats. Pain 4 (2), 161-174.

Eddy, N.B., Leimbach, D., 1953. Synthetic analgesics. II. Dithienylbutenyl- and dithienylbutylamines. J. Pharmacol. Exp. Ther. 107 (3), 385-393.

Ferreira, S.H., et al., 1978. Central and peripheral antialgesic action of aspirin-like drugs. Eur. J. Pharmacol. 53 (1), 39-48.

Ferreira, S.H., et al., 1988. Interleukin- $1 \beta$ as a potent hyperalgesic agent antagonized by a tripeptide analogue. Nature 334 (6184), 698-700.

Ferreira, S.H., et al., 1997. Role of lipocortin-1 in the anti-hyperalgesic actions of dexamethasone. Br. J. Pharmacol. 121 (5), 883-888.

Frontali, N., et al., 1976. Purification from black widow spider venom of a protein factor causing the depletion of synaptic vesicles at neuromuscular junctions. J. Cell Biol. 68 (3), 462-479.

Galvão-Nascimento, N., et al., 2010. Contribution of mast cells to the oedema induced by Bothrops moojeni snake venom and a pharmacological assessment of the inflammatory mediators involved. Toxicon 55 (2-3), 343-352 2010.

Gao, W., et al., 2016. Quercetin ameliorates paclitaxel-induced neuropathic pain by stabilizing mast cells, and subsequently blocking PKCE-dependent activation of TRPV1. Acta Pharmacol. Sin. 37 (9), 1166-1177.

Gewehr, C., et al., 2013. Mechanisms involved in the nociception triggered by the venom of the armed spider Phoneutria nigriventer. PLoS Negl. Trop. Dis. 7 (4), 1-15.

Graham, H.T., et al., 1955. Mast cells as sources of tissue histamine. J. Exp. Med. 102 (3), 307-318.

Grasso, A., 1976. Preparation and properties of a neurotoxin purified from the venom of the black widow spider (Latrodectus mactans tredecimguttatus). Biochim. Biophys. Acta 439 (2), 406-412.

Hori, T., et al., 1988. Responses of anterior hypothalamic-preoptic thermosensitive neurons to locally applied capsaicin. Neuropharmacology 27 (2), 135-142.

Jardín, I., et al., 2017. TRPs in pain sensation. Front. Physiol. 8, 392.

Jasmin, L., et al., 1998. The cold plate as a test of nociceptive behaviors: description and application to the study of chronic neuropathic and inflammatory pain models. Pain 75 (2-3), 367-382.

Kajihara, Y., et al., 2010. Histamine potentiates acid-induced responses mediating transient receptor potential V1 in mouse primary sensory neurons. Neuroscience 166 (1), 292-304.

Kitaguchi, T., et al., 2005. An inhibitor of TRPV1 channels isolated from funnel web spider venom. Biochemistry 44 (47), 15544-15549.

Kwasniewski, F.H., et al., 1998. Impairment in connective tissue mast cells degranulation in spontaneously hypertensive rats: stimulus dependent resistance. Br. J. Pharmacol. 124 (4), 772-778.

Laemmli, U.K., 1970. Cleavage of structural proteins during the assembly of the head of bacteriophage T4. Nature 227, 680-685.

Levi, H.W., 1959. The spider genus Latrodectus (Araneae, Theridiidae). Trans. Am. Microsc. Soc. 78 (1), 7-43.

Lima, M.S., et al., 2013. Anti-inflammatory effects of carvacrol: evidence for a key role of interleukin-10. Eur. J. Pharmacol. 699, 112-117.

Lima, F.O., et al., 2018. Antinociceptive effect of lupeol: evidence for a role of cytokines inhibition. Phytother. Res. 27 (10), 1557-1563.

Lira-da-Silva, R.M., et al., 1995. Estudo retrospectivo de latrodectismo na Bahia, Brasil.
Revista da Sociedade Brasileira de Medicina Tropical 28 (3), 205-210.

Liu, T., et al., 2007. Degranulation of mast cells and histamine release involved in rat pain-related behaviors and edema induced by scorpion Buthus martensi Karch venom. Eur. J. Pharmacol. 575 (1-3), 46-56.

Lucas, S.M., et al., 2003. Aranhas de interesse médico no Brasil. In: Cardoso, J.L.C. (Ed.), Animais peçonhentos no Brasil: biologia, clínica e terapêutica dos acidentes. Sarvier, São Paulo, pp. 141-149.

Maretic, Z., 1983. Latrodectism: variations in clinical manifestations provoked by Latrodectus species of spider. Toxicon 21 (4), 457-466.

Min, J.W., et al., 2013. Different types of toxins targeting TRPV1 in pain. Toxicon 71, 66-75.

Moore, S., et al., 2009. Mass spectrometric characterisation and quantitation of selected low molecular mass compounds from the venom of Haplopelma lividum (Theraphosidae). Rapid Commun. Mass Spectrom. 23 (12), 1747-1755.

Nascimento, O.A., et al., 2016. Pharmacological properties of riparin IV in models of pain and inflammation. Molecules 21 (12), 1757-1771.

Nicolson, T.A., et al., 2002. Characterisation of the calcium responses to histamine in capsaicin-sensitive and capsaicin-insensitive sensory neurones. Neuroscience 10, 329-338.

Offerman, S.R., et al., 2011. The treatment of black widow spider envenomation with antivenin Latrodectus mactans: a case series. Perm. J. 15 (3), 76-81.

Oliveira, S.M., et al., 2011. Involvement of mast cells in a mouse model of postoperative pain. Eur. J. Pharmacol. 672, 88-95.

Pansa, M.C., et al., 1972. 5-hydroxytryptamine content of Latrodectus mactans tredecimguttatus venom from gland extracts. Toxicon 10 (1), 85-86.

Perkins, M.N., et al., 1993. Antinociceptive activity of the bradykinin $\mathrm{B}_{1}$ and $\mathrm{B}_{2}$ receptor antagonits, des-Arg ${ }^{9}$, [Leu $\left.{ }^{8}\right]$-BK and HOE 140, in two models of persistent hyperalgesia in the rat. Pain 53 (1), 191-197.

Pommier, P., et al., 2005. Morsures d'araignées: les aranéismes d'importance médicale. La Presse Médicale 34 (1), 49-56.

Rash, L.D., et al., 1998. Evidence that histamine is the principal pharmacological component of venom from an Australian wolf spider (Lycosa godeffroyi). Toxicon 36 (2), 367-375.

Rash, L.D., et al., 2000. Sex differences in the pharmacological activity of venom from the white-tailed spider (Lampona cylindrata). Toxicon. 38 (8), 1111-1127.

Rattmann, Y.D., et al., 2008. Vascular permeability and vasodilation induced by the Loxosceles intermedia venom in rats: involvement of mast cell degranulation, histamine and 5-HT receptors. Toxicon 51 (3), 363-372.

Siemens, J., et al., 2006. Spider toxins activate the capsaicin receptor to produce inflammatory pain. Nature 444 (1), 208-212.

Sommer, C., 2004. Serotonin in pain and analgesia: actions in the periphery. Mol Neurobiol. 30 (2), 117-125.

Souza, C.M.V., 2012. Notas sobre o latrodectismo no Brasil. Gazeta Médica da Bahia 82 (1), 90-96.

Srebro, D., et al., 2016. Participation of peripheral TRPV1, TRPV4, TRPA1 and ASIC in a magnesium sulfate-induced local pain model in rat. Neuroscience $339,1-11$.

Sylvie, D., et al., 2015. Pain modulating peptides in spider venoms: good and evil. In: Gopalakrishnakone, P. (Ed.), Spider Venom. Springer, Amsterdam, pp. 121-154.

Tanimoto-Mori, S., et al., 2008. Pharmacologic investigation of the mechanism underlying cold allodynia using a new cold plate procedure in rats with chronic constriction injuries. Behav. Pharmacol. 19 (1), 85-90.

Távora, B.C., et al., 2016. Involvement of mast cells and histamine in edema induced in mice by Scolopendra viridicornis centipede venom. Toxicon 121 (1), 51-60.

Ushkaryov, Y.A., et al., 2004. The multiple actions of black widow spider toxins and their selective use in neurosecretion studies. Toxicon 43, 527-542.

Vetter, R.S., Isbister, G.K., 2008. Medical aspects of spider bites. Annu. Rev. Entomol. 53 (1), 409-429.

Welsh, J.H., Batty, C.S., 1963. 5-Hydroxytryptamine content of some arthropod venoms and venom-containing parts. Toxicon 1, 165-173.

Wouters, M.M., et al., 2016. Histamine receptor H1-mediated sensitization of TRPV1 mediates visceral hypersensitivity and symptoms in patients with irritable bowel syndrome. Gastroenterology 150 (4), 875-887 2016.

Yan, S., Wang, X., 2015. Recent advances in research on widow spider venoms and toxins. Toxins 7, 5055-5067.

Zanchet, E.M., Cury, Y., 2003. Peripheral tackykinin and excitatory amino acid receptors mediate hyperalgesia induced by Phoneutria nigriventer venom. Eur. J. Pharmacol. 467 (1), 111-118.

Zimmermann, M., 1983. Ethical guidelines for investigations of experimental pain in conscious animals. Pain 16 (2), 109-110. 